\title{
Neurological abnormalities and cognitive ability in first-episode psychosis
}

Paola Dazzan, Tuhina Lloyd, Kevin D. Morgan, Jolanta Zanelli, Craig Morgan, Ken Orr, Gerard Hutchinson, Paul Fearon, Matthew Allin, Larry Rifkin, Philip K. McGuire, Gillian A. Doody, John Holloway, Julian Leff, Glynn Harrison, Peter B. Jones and Robin M. Murray

\section{Background}

It remains unclear if the excess of neurological soft signs, or of certain types of neurological soft signs, is common to all psychoses, and whether this excess is simply an epiphenomenon of the lower general cognitive ability present in psychosis.

\section{Aims}

To investigate whether an excess of neurological soft signs is independent of diagnosis (schizophrenia $v$. affective psychosis) and cognitive ability (IQ).

\section{Method}

Evaluation of types of neurological soft signs in a prospective cohort of all individuals presenting with psychoses over 2 years $(n=310)$, and in a control group from the general population $(n=239)$.

\section{Results}

Primary $(P<0.001)$, motor coordination $(P<0.001)$, and motor sequencing $(P<0.001)$ sign scores were significantly higher in people with any psychosis than in the control group. However, only primary and motor coordination scores remained higher when individuals with psychosis and controls were matched for premorbid and current IQ.

\section{Conclusions}

Higher rates of primary and motor coordination signs are not associated with lower cognitive ability, and are specific to the presence of psychosis.

\section{Declaration of interest}

None. Funding detailed in Acknowledgements.
Minor 'soft' neurological abnormalities (neurological soft signs) in sensory and motor performance have been described in excess in people with established schizophrenia. ${ }^{1,2}$ Preliminary evidence, from studies using relatively small samples, suggests that higher total rates of neurological soft signs and motor problems are already present at the time of the first schizophrenia episode, ${ }^{2}$ and therefore they might be part of a vulnerability to this illness. According to the notion that schizophrenia lies with the other psychoses along a continuum of vulnerability, clarifying whether neurological soft signs are specific to schizophrenia, or common to all psychoses, will provide a better understanding of their role in the pathogenesis of these disorders.

A potential difficulty in further understanding neurological soft signs in psychosis is the fact that these abnormalities are associated with lower IQ and impaired general cognitive ability. ${ }^{3,4}$ Indeed, some authors have suggested that the concomitant presence of neurological soft signs and impaired cognitive ability could reflect the same diffuse brain disorder. ${ }^{5,6}$ Therefore, it is essential to establish if all neurological soft signs in psychosis are associated with a lower IQ, or whether their presence reflects a separate and independent dysfunction.

We evaluated neurological soft signs in a large sample of people with first-episode psychosis and in a control group without psychosis from the general population. To specifically clarify the role of general cognitive ability, we compared neurological soft signs rates in the group with first-episode psychosis and the control group while removing differences in IQ. To our knowledge, this is the first study that has conducted such a comparison. We hypothesised that: (a) neurological soft signs would be more prevalent among people with psychoses than controls from the general population, and that this would be true for both schizophrenia and affective psychosis; and (b) this excess would be explained by differences in IQ.

\section{Method}

This study forms part of the ÆSOP (Aetiology and Ethnicity in Schizophrenia and Other Psychoses) study, a population-based case-control study of all incident cases of psychosis in South-East London (2 years), Nottingham (2 years) and Bristol (9 months). Ethical approval was obtained from the local research ethics committees. Details of case ascertainment and recruitment have been detailed elsewhere. ${ }^{7}$

\section{Participants}

We approached all individuals, aged 16-64 years, and resident within the study areas, who consecutively presented to the local psychiatric services for a first-in-lifetime functional psychotic illness. Inclusion criteria were:

(a) absence of an organic medical cause or profound intellectual disability;

(b) absence of a history of head trauma resulting in loss of consciousness for over $1 \mathrm{~h}$;

(c) presence of a functional psychotic illness (ICD-10 F10-19, excluding coding F1x.0 for Acute intoxication; F20-29 and F30-39, psychotic codings); ${ }^{8}$

(d) no previous contact with psychiatric services for psychotic symptoms.

A group of controls, aged 16-64 years, was also recruited from residents within the study areas using household visits, local press advertisements and advertisement for hospital staff for a minority of cases. ${ }^{9}$ We were particularly careful with recruiting a sample representative of the general population, and for this reason we included a sampling procedure adapted from that used by the Office of Population and Census Statistics Psychiatric Morbidity 
Survey. ${ }^{9}$ Individuals were screened for the presence of psychotic symptoms with the Psychosis Screening Questionnaire, ${ }^{10}$ and excluded if they screened positive.

\section{Clinical evaluation}

We collected socio-demographic data for all individuals. The psychosis group were interviewed using the Schedule for Clinical Assessment in Neuropsychiatry (SCAN).$^{11}$ We made a diagnosis according to ICD-10 criteria $^{8}$ by consensus in meetings with senior clinicians (R.M.M., J.L., P.B.J., G.A.D. or G.H.) from our institutions, in which all clinical information was presented. Interrater and intercentre reliability for diagnosis was high $(80 \%$ agreement on diagnostic category; kappa values ranging from 0.63 to 0.75$)$.

A total symptom score was obtained by summing the SCAN's individual symptom item scores as per procedures used by Wing et $a l^{12}$ and Wing \& Sturt. ${ }^{13}$ Data relating to date of onset of psychosis was collated using the Personal and Psychiatric History Schedule. $^{14}$

Premorbid IQ was estimated by the National Adult Reading Test (NART). ${ }^{15}$ Current full-scale IQ was assessed using a shortened form of the revised Wechsler Adult Intelligence Scale (WAIS-R) ${ }^{16}$ Handedness was assessed with the Annett Hand Preference Questionnaire. ${ }^{17}$

\section{Neurological evaluation}

We assessed neurological function as soon as possible after initial presentation, with an expanded, previously validated, version of the Neurological Evaluation Scale ${ }^{1,18}$ (see online supplement to this article). This version is composed of four sub-scales, reflecting different functional areas and showing good construct validity: ${ }^{19}$

(a) 'primary neurological dysfunction' (dysfunction that can be identified by a standard neurological examination);

(b) 'sensory integration dysfunction' (dysfunction in the integration of sensory information);

(c) 'motor coordination dysfunction' (motor incoordination);

(d) 'motor sequencing dysfunction' (performance of complex motor sequences).

Assessment of neurological soft signs was always performed by a physician masked to diagnosis, and interrater reliability was good ( $r=0.87$ to 0.96$).{ }^{20}$ Information on item scoring is provided in the online supplement. We analysed each sub-scale score separately, as this better represents the diversity of neurological dysfunction than the evaluation of the global score. ${ }^{19}$

Extrapyramidal symptoms were evaluated with the SimpsonAngus scale, ${ }^{21}$ akathisia with the Barnes Akathisia Rating Scale, ${ }^{22}$ and tardive dyskinesia with the Abnormal Involuntary Movement in Schizophrenia scale. ${ }^{23}$

\section{Statistical analysis}

Descriptive data are presented as individual values, mean (s.d.). Socio-demographic and neurological sign differences between groups were compared using unpaired $t$-test, ANOVA, or chisquared test, as appropriate. We used two-way ANCOVA analyses to investigate the role of potential confounders and interactions. Finally, correlational analyses were used to investigate correlations between factors. Statistical analyses were performed using SPSS 12.0 statistical software for Windows.

\section{Results}

A total of 468 individuals with first-episode psychosis were approached. Of these, 310 completed a neurological evaluation ( $n=146$ schizophrenia, $n=113$ affective psychosis, $n=51$ other psychosis), while 78 refused to take part in the study and 80 did not complete the neurological evaluation. Demographic and clinical characteristics of the whole incidence sample are detailed in Kirkbride et al. ${ }^{7}$ We also recruited 239 people from the general population to act as a control group. Characteristics of the participants included in these analyses are presented in Table 1. There were no differences between the group with first-episode psychosis and the control group for age, gender and handedness. The psychosis group had significantly less individuals of White ethnicity $\left(\chi^{2}=29\right.$, d.f. $\left.=1, P<0.001\right)$, and had significantly lower premorbid IQ $(t=7.4$, d.f. $=433, P<0.001)$ and current full-scale IQ $(t=9$, d.f. $=400, P<0.001)$ than the control group (Table 1).

\section{Neurological soft signs in the psychosis group v. controls}

In comparison with controls ( $t$-test) individuals with psychosis had significantly higher mean scores of total signs $(t=-6$, d.f. $=547, P<0.001)$, and primary $(t=-3.6$, d.f. $=547, P<0.001)$, motor coordination $(\mathrm{t}=-8$, d.f. $=547, P<0.001)$ and motor sequencing $(t=-4$, d.f. $=547, P<0.001)$ signs, although they had similar scores of sensory integration signs (Table 1). At least one sign (considered as present only when scored 2) was present in $48.4 \%$ of the psychosis group compared with $38.5 \%$ of controls $\left(\chi^{2}=5.6, P=0.02\right)$ (Table DS1). In agreement with our hypothesis, there were no differences between diagnostic groups (ANOVA) for scores of total neurological soft signs, or for any of the four neurological soft signs sub-scales (Table 2).

To exclude the possibility that differences between the two groups might have been because the group with psychosis were taking antipsychotic drugs, we removed, from the primary scale, signs that could be induced by antipsychotic medication: chorea, tremor, mirror movements and primitive reflexes. Even when these signs were removed, individuals with psychosis had significantly higher primary scores than controls $(2($ s.d. $=2.5)$ in participants with psychois $v .1 .4$ (s.d.=1.9) in the control group; $t=-3.2$, d.f.=547, $P=0.002$ ).

\section{The role of ethnicity, gender, age and IQ}

As ethnic composition was significantly different in the two groups, we investigated the role of ethnicity with a two-way ANCOVA analysis using group (psychosis $v$. control) and ethnicity (White $v$. Black and minority ethnic) as fixed factors. There was no effect of ethnicity on any of the neurological soft sign scores (all $P>0.15$ ). There was also no ethnicity $\times$ group interaction for any of the scales (all $P>0.1$ ). Moreover, participants with psychosis of White ethnicity and of Black and minority ethnic groups had higher neurological soft sign scores than the control group of the same ethnic group (all $P$-values for total neurological soft signs score $<0.001$ ). Therefore, ethnicity does not seem to be a confounding factor in the neurological soft sign differences between those with and without psychosis.

We explored the role of gender by conducting a two-way ANOVA analysis, using the neurological soft sign scores at each of the neurological soft sign sub-scales and the total neurological soft signs score as the dependent variables, and group membership and gender as fixed factors. This showed that there was a significant gender $\times$ group interaction for primary signs $(F=7.6$, d.f. $=1$, $P=0.006)$, motor sequencing signs $(F=4.2$, d.f. $=1, P=0.04)$, and 


\begin{tabular}{|c|c|c|c|}
\hline Characteristic & $\begin{array}{l}\text { Individuals with psychosis } \\
\qquad n=310\end{array}$ & $\begin{array}{c}\text { Controls } \\
n=239\end{array}$ & $\begin{array}{c}P \\
\left(t \text {-test } / \chi^{2} \text {-test) }\right.\end{array}$ \\
\hline Female gender, $n(\%)$ & $132(43)$ & $119(50)$ & 0.09 \\
\hline Age, years: median (interquartile range) & $28(22-38)$ & $29(19-40)$ & ns \\
\hline Handedness, $n$ (\% right) & $276(90)$ & $216(92)$ & ns \\
\hline $\begin{array}{l}\text { Ethnicity, \% } \\
\text { White } \\
\text { Black and minority ethnic }\end{array}$ & $\begin{array}{l}58 \\
42\end{array}$ & $\begin{array}{l}80 \\
20\end{array}$ & $<0.001$ \\
\hline Premorbid IQ: mean NART (s.d.) ${ }^{\mathrm{a}}$ & $97.6(14)$ & $106.9(12)$ & $<0.001$ \\
\hline $\begin{array}{l}\text { Current IQ: mean WAIS-R (s.d.) } \\
\text { Full-scale } \\
\text { Performance } \\
\text { Verbal }\end{array}$ & $\begin{array}{l}90.7(15) \\
90.3(19) \\
92.2(17)\end{array}$ & $\begin{array}{l}105.3(15) \\
105.8(15) \\
103.9(16)\end{array}$ & $\begin{array}{l}<0.001 \\
<0.001 \\
<0.001\end{array}$ \\
\hline Duration of untreated illness, weeks: median (interquartile range) & $8(2-38)$ & - & - \\
\hline Duration of illness, weeks: median (interquartile range) & $26(10-74)$ & - & - \\
\hline $\begin{array}{l}\text { SCAN symptoms: mean (s.d.) } \\
\text { Positive symptoms } \\
\text { Depressive symptoms } \\
\text { Hypomania symptoms } \\
\text { Negative symptoms } \\
\text { Total symptoms }\end{array}$ & $\begin{array}{r}5.9(4.3) \\
1.3(1.8) \\
1.4(2.2) \\
0.4(0.7) \\
11.2(5.8)\end{array}$ & - & - \\
\hline AlMS: mean (s.d.) & $0.66(2.1)$ & - & - \\
\hline Barnes: mean (s.d.) & $1.22(2.4)$ & - & - \\
\hline Simpson-Angus: mean (s.d.) & $1.8(2.7)$ & - & - \\
\hline $\begin{array}{l}\text { Neurological soft signs: mean (s.d); (quartiles) } \\
\text { Primary } \\
\text { Sensory integration } \\
\text { Motor coordination } \\
\text { Motor sequencing } \\
\text { Total }\end{array}$ & $\begin{array}{ll}3.3 & (3.5) ;\left(\begin{array}{lll}0 & 2 & 5\end{array}\right) \\
1 & (1.4) ;\left(\begin{array}{lll}0 & 0 & 2\end{array}\right) \\
2 & (2.4) ;\left(\begin{array}{lll}0 & 1 & 3\end{array}\right) \\
2.6 & (2.9) ;\left(\begin{array}{lll}0 & 2 & 5\end{array}\right) \\
8.7 & (7.4) ;\left(\begin{array}{lll}3 & 8 & 13\end{array}\right)\end{array}$ & $\begin{array}{l}2.3(2.8) ;\left(\begin{array}{lll}0 & 1 & 4\end{array}\right) \\
0.8(1.2) ;\left(\begin{array}{lll}0 & 0 & 1\end{array}\right) \\
0.6 \text { (1.4); }\left(\begin{array}{lll}0 & 0 & 0\end{array}\right) \\
1.7(2.2) ;\left(\begin{array}{lll}0 & 1 & 2\end{array}\right) \\
5.3(5.3) ;\left(\begin{array}{lll}2 & 4 & 7\end{array}\right)\end{array}$ & $\begin{array}{l}<0.001 \\
\quad \text { ns } \\
<0.001 \\
<0.001 \\
<0.001\end{array}$ \\
\hline
\end{tabular}

total neurological soft signs ( $F=6.1$, d.f. $=1, P=0.01)$. Specifically, within controls, male controls had higher scores for total neurological soft signs $(F=9.4$, d.f. $=237, P=0.009)$ and primary signs $(F=10.7$, d.f. $=237, P<0.001)$ than female controls. In contrast, within the psychosis group, males had neurological soft signs scores similar to females, although there was a trend for males to have less motor sequencing signs than females.

In both groups, an older age was correlated with higher sensory integration and motor sequencing scores (Table 3); in the psychosis group, older age was additionally associated with higher motor coordination and total neurological soft sign scores (Table 3).

Finally, we examined the role of premorbid and current IQ using a two-tailed correlation (Pearson's $r$ ) between IQ and each of the neurological soft sign sub-scales and total neurological soft signs score (Table 3). In the psychosis group, both lower premorbid and current IQ were correlated with higher scores on all neurological soft sign sub-scales. In the control group, lower current IQ was correlated with higher scores in all neurological soft sign scales except the primary signs, while a lower premorbid IQ was only correlated with higher sensory integration and motor sequencing scores. The results were grossly similar when verbal and performance components of current IQ were analysed separately. Therefore, in all further analyses we entered current IQ as full-scale score. Because individuals with psychosis had lower IQ than controls, it was unclear at this stage whether the excess of neurological soft signs in people with psychosis was simply a consequence of the lower IQ.
Having found that age, gender and IQ affect neurological soft sign scores, we performed a two-way ANCOVA analysis, using group membership and gender as the fixed factors, and age and premorbid and current IQ as covariates. Even when covarying for these factors, there was still a significant effect of group, with the psychosis group showing higher scores than controls for primary signs $(F=12$, d.f. $=1, P=0.001$, estimated mean difference +1.1 (s.e.m $=0.3)$ ) and motor coordination signs $(F=46$, d.f. $=1$, $P<0.001$, estimated mean difference +1.3 (s.e. $m=0.2)$ ). However, the previous difference identified in motor sequencing scores was no longer significant ( $F=2$, d.f. $=1, P=0.2$, estimated mean difference +0.3 (s.e.m $=0.2)$ ). Moreover, there continued to be no statistically significant difference between the two groups in scores of sensory integration signs ( $F=1$, d.f. $=1, P=0.3$, estimated mean difference -0.1 (s.e.m=0.1)).

\section{Neurological soft signs in participants with psychosis and controls matched for age, gender and IQ}

To confirm the results of the covariate analysis, we compared neurological soft sign scores in individuals with psychosis $(n=145)$ and controls $(n=145)$ that were matched individually for a 5-point premorbid IQ band as well as for a 5-year age band and for gender. As previously found in the covariate analysis, also in this matched comparison individuals with psychosis had significantly higher scores only of primary $(t=-2.6$, d.f. $=288$, $P=0.01)$ and motor coordination signs $(t=-6.1$, d.f. $=288$, $P<0.001)$. In contrast, scores of sensory integration and motor 


\begin{tabular}{|c|c|c|c|c|}
\hline Characteristic & $\begin{array}{c}\text { Schizophrenia } \\
n=146\end{array}$ & $\begin{array}{l}\text { Affective psychosis } \\
\qquad n=113\end{array}$ & $\begin{array}{l}\text { Other psychosis } \\
\qquad n=51\end{array}$ & $P$ \\
\hline Gender, $n$ (\% female) & $52(36)$ & $64(57)$ & $16(31)$ & $0.001^{a}$ \\
\hline Age, years: median (interquartile range) & $26(20-35)$ & $32(24-40)$ & $29(21-38)$ & $0.04^{\mathrm{b}}$ \\
\hline Premorbid IQ: mean NART (s.d.) & $95.4(14.7)$ & $101.1(13.1)$ & $96(12.8)$ & $0.02^{c}$ \\
\hline Current full-scale IQ: mean WAIS-R (s.d.) & $87.3(17)$ & $94.4(17)$ & $92.2(15)$ & $0.009^{d}$ \\
\hline \multicolumn{5}{|l|}{ Neurological soft signs: mean (s.d.) } \\
\hline Primary & $3.3(3.4)$ & $3.2(3.8)$ & $3.4(3.5)$ & 1 \\
\hline Sensory integration & 1 (1.4) & $0.7(1.2)$ & $1.3(1.6)$ & 0.07 \\
\hline Motor coordination & $2(2.5)$ & $1.9(2.3)$ & $2.3(2.5)$ & 0.7 \\
\hline Motor sequencing & $2(2.9)$ & $2.4 \quad(3)$ & $2.4(2.7)$ & 0.6 \\
\hline Total & $9 \quad(7.4)$ & $8.2(7.4)$ & $9.3(7.4)$ & 0.6 \\
\hline AIMS: mean (s.d.) & $0.6(2.2)$ & $0.8(2.3)$ & $0.4(1.2)$ & 0.5 \\
\hline Barnes: mean (s.d.) & $1.1(2.1)$ & $1.5(2.8)$ & $0.9(2.1)$ & 0.4 \\
\hline Simpson-Angus: mean (s.d.) & $2.2(3.2)$ & $1.6(2.1)$ & $1.5(2.1)$ & 0.1 \\
\hline \multicolumn{5}{|c|}{$\begin{array}{l}\text { AIMS, Abnormal Involuntary Movement Scale; Barnes, Barnes Akathisia Rating Scale; NART, National Adult Reading Test; WAIS-R, Wechsler Adult Intelligence Scale - revised. } \\
\text { a. POSt hoc analysis: affective psychosis group had more females than the schizophrenia and the other psychosis groups }(P=0.001 \text { and } P=0.003 \text { respectively). } \\
\text { b. Post hoc analysis: schizophrenia group was significantly younger than the affective psychosis group ( } P=0.01) \text {. } \\
\text { C. Information on NART IQ was obtained for } 227 \text { individuals with psychosis; post hoc analysis showed that the schizophrenia group had a significantly lower IQ than the affective } \\
\text { psychosis group ( } P=0.02) \text {. } \\
\text { d. Information on WAIS-R IQ was obtained for } 240 \text { with psychosis; post hoc analysis showed that the schizophrenia group had a significantly lower IQ than the affective psychosis } \\
\text { group ( } P=0.008) \text {. }\end{array}$} \\
\hline
\end{tabular}

sequencing scores were similar in the two groups. Finally, we repeated the analysis in a subgroup of those with psychosis and controls ( $n=114$ in each group) additionally matched for current IQ (which also includes non-verbal ability). Even in this comparison, participants with psychosis continued to display an excess of primary $(t=-2.7$, d.f. $=226, P=0.007)$ and motor coordination $(t=-5.4$, d.f. $=226, P<0.001)$ signs, while sensory integrative and motor sequencing signs scores were similar in both groups.

\section{Discussion}

In the largest sample of people with first-episode psychoses studied to date, we have established that from the onset of the illness, individuals with both schizophrenia and affective psychoses have higher neurological soft sign scores than a control group from the general population, thus confirming our first hypothesis. In contrast to our second hypothesis, we have established that these higher scores are not fully explained by differences in IQ. In particular, although higher motor sequencing scores are associated with a lower premorbid IQ, the higher primary and motor coordination scores are independent from general cognitive ability and therefore may have a different pathophysiological substrate. The presence of a neurological dysfunction at this initial stage of psychosis is unlikely to have been the consequence of illness-related degenerative processes, as the individuals we investigated had only been ill for a median of approximately 6 months.

In comparison with studies that used the same scale, the neurological soft sign rates we observed in individuals with first-episode psychosis were rather low. ${ }^{24,25}$ It is possible that people at their first psychotic episode show fewer neurological soft signs than those at more advanced stages of the illness, ${ }^{26}$ in whom a worse neurological dysfunction may be related to the disease progression. It is also possible that other studies have used a less conservative approach to scoring, hence their higher values. ${ }^{27}$ Indeed our rates are similar to those found by Griffiths et al, ${ }^{18}$ who used our same conservative approach, always scoring equivocal signs at the lower value.

We could test our first hypothesis, that neurological soft sign rates would be similar across all psychoses, because of the large number of individuals with 'affective' and with 'other' psychoses evaluated in this study. We found that rates of neurological abnormalities are similar across schizophrenia, affective psychoses and other types of psychosis. Our data strongly suggest that neurological abnormalities are not specific to any diagnosis of psychoses, a similar finding to the only other existing study that also evaluated neurological soft signs in first-episode affective psychosis and also to data suggesting an excess of soft signs in

Table 3 Correlation between neurological soft signs and age and IQ in the psychosis and control groups

\begin{tabular}{|c|c|c|c|c|c|c|c|c|c|c|c|c|}
\hline \multirow{3}{*}{$\begin{array}{l}\text { Neurological } \\
\text { soft signs }\end{array}$} & \multicolumn{4}{|c|}{ Age } & \multicolumn{4}{|c|}{ Premorbid IQ } & \multicolumn{4}{|c|}{ Current IQ } \\
\hline & \multicolumn{2}{|c|}{ Psychosis group } & \multicolumn{2}{|c|}{ Control group } & \multicolumn{2}{|c|}{ Psychosis group } & \multicolumn{2}{|c|}{ Control group } & \multicolumn{2}{|c|}{ Psychosis group } & \multicolumn{2}{|c|}{ Control group } \\
\hline & $r$ & $P$ & $r$ & $P$ & $r$ & $P$ & $r$ & $P$ & $r$ & $P$ & $r$ & $P$ \\
\hline Primary & -0.008 & 0.9 & -0.11 & 0.08 & -0.13 & 0.04 & 0.07 & 0.3 & -0.2 & $<0.001$ & -0.04 & 0.7 \\
\hline $\begin{array}{l}\text { Sensory } \\
\text { integration }\end{array}$ & 0.11 & 0.06 & 0.24 & $<0.001$ & -0.25 & $<0.001$ & -0.24 & $<0.001$ & -0.3 & $<0.001$ & -0.23 & 0.003 \\
\hline $\begin{array}{l}\text { Motor } \\
\text { coordination }\end{array}$ & 0.10 & 0.07 & -0.29 & 0.7 & -0.12 & 0.07 & 0.05 & 0.5 & -0.2 & 0.001 & -0.17 & 0.03 \\
\hline $\begin{array}{l}\text { Motor } \\
\text { sequencing }\end{array}$ & 0.17 & 0.003 & 0.14 & 0.03 & -0.29 & $<0.001$ & -0.19 & 0.005 & -0.2 & $<0.001$ & -0.26 & 0.001 \\
\hline Total & 0.12 & 0.04 & 0.04 & 0.5 & -0.27 & $<0.001$ & -0.11 & 0.1 & -0.3 & $<0.001$ & -0.27 & $<0.001$ \\
\hline
\end{tabular}


bipolar disorder. ${ }^{28,29}$ Furthermore, even the differences in rates between individuals with different psychoses and controls were relatively modest, suggesting that neurological soft signs are not a robust concomitant of any psychoses.

To test our second hypothesis, we investigated whether higher neurological soft sign scores could be explained by lower IQ in the psychosis group, and we found that only higher primary and motor coordination scores are not related to worse general cognitive ability. Interestingly, among primary signs, participants with psychosis particularly showed an excess of gaze impersistence, a common early sign of Huntington disease and therefore possibly related to dopamine dysfunction, the neurotransmitter most often implicated in the pathophysiology of schizophrenia. Consistent with our findings, Arango et $a l^{3}$ reported that frontal release and eye movement signs (included in the primary subscale) were the only signs present in excess in those with schizophrenia and a high IQ. The excess of motor coordination signs in individuals with psychosis may reflect abnormalities of the basal ganglia, brain structures regulating movement which our and another group have found to be smaller in size in individuals who are psychotic and have motor abnormalities. ${ }^{20,30}$ Motor coordination problems may also reflect dysfunction of another structure possibly involved in the pathogenesis of psychosis, the cerebellum. $^{31}$

In contrast to primary and motor coordination scores, we found that motor sequencing scores were similar in people with and without psychosis, once IQ was taken into account. It is possible that previous reports of higher motor sequencing scores in individuals with schizophrenia compared with controls were related to a lower IQ in the schizophrenia group. ${ }^{3,32-35}$ In fact, none of these studies used a comparison group matched for IQ. Interestingly, and consistent with our results, Arango et al found no differences in motor sequencing signs in a sub-analysis of their sample that compared only participants who had psychosis and a high IQ with controls. Taken together, these findings suggest that motor sequencing signs in psychosis may share the same pathophysiological substrate underlying lower general cognitive ability.

Finally, we found that sensory integration signs were similar in people with and without psychosis, even without taking IQ into account. This finding is in contrast with previous studies, mostly non-epidemiological, conducted on individuals with chronic psychosis, and in relatively small samples, which reported an excess of neurological soft signs across all scales. ${ }^{3,36}$ It is possible that sensory integrative deficits become more apparent at later stages of the illness, and therefore they are not yet present at the first episode. ${ }^{32}$ Moreover, the higher neurological soft sign scores in controls were indeed in the sensory integration sub-scale, as also shown by other studies. ${ }^{3,37}$ Our finding of similar sensory integrative rates in those with and without psychosis is also consistent with imaging data from our group, showing that both people with psychosis and controls with an excess of these signs share the same neuroanatomical abnormalities, that is, frontal and temporal lobe reductions. ${ }^{20,38}$ This is in contrast with the above-mentioned evidence that other structures such as the basal ganglia are reduced only in those participants with psychosis who have motor dysfunction and not in controls with the same dysfunction. Therefore, the excess of neurological soft signs involving motor coordination skills or reflecting 'focal' deficits, seems to be independent of IQ and may reflect a dysfunction of brain areas specifically affected by psychosis. On the contrary, neurological soft signs that require the integration of different sensory information are present to the same extent in people with psychosis and in the general population and may reflect a more general brain dysfunction, localised in the same brain areas in both groups, and therefore not associated with the pathogenesis of this illness.

It is interesting that, although significantly lower than those of individuals with psychosis, neurological soft signs were relatively common among controls, with $38.5 \%$ showing at least one sign. This percentage and the neurological soft sign score we observed in controls are consistent with reports from other studies that have used the Neurological Evaluation Scale in controls. ${ }^{32,35,36}$

A potential limitation of this study is that assessors were not always masked to group status (psychosis $v$. control). This is because masking is difficult to maintain in this type of population, as those with psychosis often display mannerisms and drugrelated extrapyramidal features that are difficult to mask. However, it is interesting that in our study people with psychosis scored higher only on certain sub-scales. As assessors were masked to study hypotheses, it is unlikely that identifying someone as an individual with psychosis affected only certain neurological soft sign sub-scales.

In conclusion, this study provides evidence that an excess of primary and motor coordination signs may be specific to the presence of a psychosis and is not related with lower general cognitive ability.

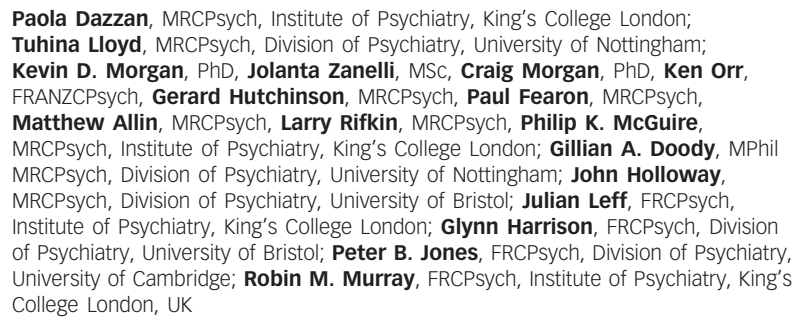

Paola Dazzan, MRCPsych, Institute of Psychiatry, King's College London; Tuhina Lloyd, MRCPsych, Division of Psychiatry, University of Nottingham; Kevin D. Morgan, PhD, Jolanta Zanelli, MSc, Craig Morgan, PhD, Ken orr, FRANZCPsych, Gerard Hutchinson, MRCPsych, Paul Fearon, MRCPsych, Matthew Allin, MRCPsych, Larry Rifkin, MRCPsych, Philip K. McGuire, MRCPsych, Institute of Psychiatry, King's College London; Gillian A. Doody, MPhil MRCPsych, Division of Psychiatry, University of Nottingham; John Holloway, MRCPsych, Division of Psychiatry, University of Bristol; Julian Leff, FRCPsych, MRCPSych, Division of PSychiatry, University of Bristol; Julian Leff, FRCPSych,
Institute of Psychiatry, King's College London; Glynn Harrison, FRCPsych, Division of Psychiatry, University of Bristol; Peter B. Jones, FRCPsych, Division of Psychiatry, University of Cambridge; Robin M. Murray, FRCPsych, Institute of Psychiatry, King's College London, UK

Correspondence: Paola Dazzan, Department of Psychiatry, Box 63, Institute of Psychiatry, De Crespigny Park, London SE5 8AF, UK. Email: p.dazzan@iop.kcl.ac.uk

First received 20 Sep 2007, final revision 7 Mar 2008, accepted 28 Mar 2008

\section{Acknowledgements}

We wish to acknowledge the contributions of the entire AESOP study team, listed on line at http://www.psychiatry.cam.ac.uk/aesop, and of Dr A. Reichenberg for his advice on the statistical analyses. This study was funded by the UK Medical Research Council. We also wish to thank the Stanley Medical Research Institute for their support. Paola Dazzan's research is supported by the American Psychiatric Institute for Research and Education, NARSAD (National Alliance for Research on Schizophrenia and Depression) and the Bial Foundation. The stud Foundajon. The study is part of the NHR Biomedical Research Centre for Mental Health, South London and Maudsley NHS Foundation Trust and Institute of Psychiatry, King's College London.

\section{References}

1 Buchanan RW, Heinrichs DW. The neurological evaluation scale (NES): a structured instrument for the assessment of neurological signs in schizophrenia. Psychiatry Res 1989; 27: 335-50.

2 Dazzan P, Murray RM. Neurological soft signs in first-episode psychosis: a systematic review. Br J Psychiatry 2002; 181 (suppl 43): s50-7.

3 Arango C, Bartko JJ, Gold JM, Buchanan RW. Prediction of neuropsychological performance by neurological signs in schizophrenia. Am J Psychiatry 1999; 156: $1349-57$

4 Mohr F, Hubmann W, Albus M, Franz U, Hecht S, Scherer J, Binder J, Sobizack N. Neurological soft signs and neuropsychological performance in patients with first episode schizophrenia. Psychiatry Res 2003; 121: 21-30.

5 Flashman LA, Flaum M, Gupta S, Andreasen NC. Soft signs and neuropsychological performance in schizophrenia. Am J Psychiatry 1996; 153: $526-32$.

6 King DJ, Wilson A, Cooper SJ, Waddington JL. The clinical correlates of neurological soft signs in chronic schizophrenia. Br J Psychiatry 1991; 158: 770-5. 
7 Kirkbride JB, Fearon P, Morgan C, Dazzon P, Morgan K, Tarrant J, Lloyd T, Holloway J, Hutchinson G, Leff JP, Mallet RM, Harrison GL, Murray RM, Jones PB. Heterogeneity in incidence rates of schizophrenia and other psychotic syndromes: findings from the 3-center AeSOP study. Arch Gen Psychiatry 2006; 63: 250-8

8 World Health Organization. The ICD-10 Classification of Mental and Behavioural Disorders: Clinical Descriptions and Diagnostic Guidelines. WHO 1992.

9 Morgan C, Dazzan P, Morgan K, Jones P, Harrison G, Leff J, Murray K, Fearon P; AESOP study group. First episode psychosis and ethnicity: initial findings from the AESOP study. World Psychiatry 2006; 5: 40-6.

10 Bebbington P, Nayani T. The Psychosis Screening Questionnaire. Int J Methods Psychiatr Res 1995; 5: 11-9.

11 World Health Organization. Schedules for Clinical Assessment in Neuropsychiatry (SCAN) - Version 2.0. WHO, 1992

12 Wing JK, Cooper JE, Sartorius N. The Measurement and Classification of Psychiatric Symptoms. Cambridge University Press, 1974.

13 Wing JK, Sturt E. The PSE-ID-CATEGO System: Supplementary Manual. Medical Research Council, 1978.

14 World Health Organization. Personal and Psychiatric History Schedule. WHO 1996.

15 Nelson HE, Willison JR. National Adult Reading Test (part II) Test Manual. nferNelson, 1991.

16 Wechsler D. Wechsler Adult Intelligence Scale - Revised (Manual). The Psychological Corporation, 1981.

17 Annett M. A classification of hand preference by association analysis. Br J Psychol 1970; 61: 303-21.

18 Griffiths TD, Sigmundsson T, Takei N, Rowe D, Murray RM. Neurological abnormalities in familial and sporadic schizophrenia. Brain 1998; 121: 191-203.

19 Sanders RD, Keshavan MS, Forman SD, Pieri JN, McLaughlin N, Allen DN, van Kammen DP, Goldstein G. Factor structure of neurologic examination abnormalities in unmedicated schizophrenia. Psychiatry Res 2000; 95: 237-43

20 Dazzan $\mathrm{P}$, Morgan KD, Orr KG, Hutchinson G, Chitnis X, Suckling J, Fearon $\mathrm{P}$, Salvo J, McGuire PK, Mallet RM, Jones PB, Leff J, Murray RM. The structura brain correlates of neurological soft signs in AESOP first-episode psychoses study. Brain 2004; 127: 143-53.

21 Simpson GM, Angus JWS. A rating scale for extrapyramidal side effects. Acta Psychiatr Scand Suppl 1970; 212: 11-9.

22 Barnes TRE. A rating scale for drug induced akathisia. Br J Psychiatry 1989; 154: 676.

23 National Institute of Mental Health. Abnormal Involuntary Movement Scale (AIMS). In ECDEU: Assessment Manual for Psychopharmacology (ed W Guy): 534-7. Department of Health, Education and Welfare, 1976

24 Browne S, Clarke M, Gervin M, Lane A, Waddington JL, Larkin C, $\mathrm{O}^{\prime}$ Callaghan E. Determinants of neurological dysfunction in first episode schizophrenia. Psychol Med 2000; 30: 1433-41.
25 Emsley R, Turner HJ, Oosthuizen PP, Carr J. Neurological abnormalities in first-episode schizophrenia: temporal stability and clinical and outcome correlates. Schizophr Res 2005; 75: 35-44.

26 Madsen AL, Vorstrup S, Rubin P, Larsen JK, Hemmingsen R. Neurologica abnormalities in schizophrenic patients: a prospective follow-up study 5 years after first admission. Acta Psychiatr Scand 1999; 100: 119-25

27 Cox SM, Ludwig AM. Neurological soft signs and psychopathology. I. Findings in schizophrenia. J Nerv Ment Dis 1979; 167: 161-5.

28 Goswami U, Sharma A, Khastigir U, Ferrier IN, Young AH, Gallagher P, Thompson JM, Moore PB. Neuropsychological dysfunction, soft neurological signs and social disability in euthymic patients with bipolar disorder. Br J Psychiatry 2006; 188: 366-73.

29 Whitty $\mathrm{P}$, Clarke M, McTigue O, Browne S, Gervin M, Kamali M, Lane A, Knsella A, Waddington J, Larkin C, O'callaghan E. Diagnostic specificity and predictors of neurological soft signs in schizophrenia, bipolar disorder and other psychoses over the first 4 years of illness. Schizophr Res 2006; 86 $110-7$.

30 Keshavan MS, Sanders RD, Sweeney JA, Diwadkar VA, Goldstein G, Pettegrew JW, Schooler NR. Diagnostic specificity and neuroanatomical validity of neurological abnormalities in first-episode psychoses. Am J Psychiatry 2003; 160: 1298-304.

$31 \mathrm{Ho}$ BC, Mola C, Andreasen NC. Cerebellar dysfunction in neuroleptic naive schizophrenia patients: clinical, cognitive, and neuroanatomic correlates of cerebellar neurologic signs. Biol Psychiatry 2004; 55: 1146-53.

32 Mohr F, Hubmann W, Cohen R, Bender W, Haslacher C, Hönicke S, Schlenker R, Wahheim C, Werther P. Neurological soft signs in schizophrenia: assessment and correlates. Eur Arch Psychiatry Clin Neurosci 1996; 246 : 240-8.

33 Sanders RD, Keshavan MS, Schooler NR. Neurological examination abnormalities in neuroleptic-naive patients with first-break schizophrenia: preliminary results. Am J Psychiatry 1994; 151: 1231-3.

34 Venkatasubramanian G, Latha V, Gangadhar BN, Janakiramaiah N, Subbakrishna DK, Jayakumar PN, Keshavan MS. Neurological soft signs in never-treated schizophrenia. Acta Psychiatr Scand 2003; 108: 144-6.

35 Yazici AH, Demir B, Yazici KM, Gogus A. Neurological soft signs in schizophrenic patients and their nonpsychotic siblings. Schizophr Res 2002 58: 241-6.

36 Lawrie SM, Byrne M, Miller P, Hodges A, Clafferty RA, Cunningham Owen DG, Johnson EC Neurodevelopmental indices and the development of psychotic symptoms in subjects at high risk of schizophrenia. Br J Psychiatry 2001 178: $524-30$.

37 Cuesta MJ, Peralta V, Zarzuela A, Calvo R, Garcia M, Serrano F. Neurological soft-signs in psychosis: threshold criteria for discriminating normal controls and for predicting cognitive impairment. Schizophr Res 2002; 58: 263-71.

38 Dazzan $\mathrm{P}$, Morgan KD, Chitnis X, Suckling J, Morgan C, Fearon P, McGuire PK, Jones PB, Leff J, Murray RM. The structural brain correlates of neurological soft signs in healthy individuals. Cereb Cortex 2005; 16: 1225-31. 